IZA DP No. 7648

Education and Health: The Role of Cognitive Ability

Govert Bijwaard

Hans van Kippersluis

Justus Veenman

September 2013

Forschungsinstitut zur Zukunft der Arbeit Institute for the Study of Labor 


\title{
Education and Health: The Role of Cognitive Ability
}

\author{
Govert Bijwaard \\ Netherlands Interdisciplinary Demographic Institute (NIDI) \\ and IZA \\ Hans van Kippersluis \\ Erasmus School of Economics, Erasmus University Rotterdam, \\ Tinbergen Institute and Netspar \\ Justus Veenman \\ Erasmus School of Economics, Erasmus University Rotterdam \\ and ERCOMER
}

Discussion Paper No. 7648
September 2013

IZA

P.O. Box 7240

53072 Bonn

Germany

Phone: +49-228-3894-0

Fax: +49-228-3894-180

E-mail: iza@iza.org

\begin{abstract}
Any opinions expressed here are those of the author(s) and not those of IZA. Research published in this series may include views on policy, but the institute itself takes no institutional policy positions. The IZA research network is committed to the IZA Guiding Principles of Research Integrity.

The Institute for the Study of Labor (IZA) in Bonn is a local and virtual international research center and a place of communication between science, politics and business. IZA is an independent nonprofit organization supported by Deutsche Post Foundation. The center is associated with the University of Bonn and offers a stimulating research environment through its international network, workshops and conferences, data service, project support, research visits and doctoral program. IZA engages in (i) original and internationally competitive research in all fields of labor economics, (ii) development of policy concepts, and (iii) dissemination of research results and concepts to the interested public.
\end{abstract}

IZA Discussion Papers often represent preliminary work and are circulated to encourage discussion. Citation of such a paper should account for its provisional character. A revised version may be available directly from the author. 


\section{ABSTRACT}

\section{Education and Health: The Role of Cognitive Ability*}

We aim to disentangle the relative contributions of (i) cognitive ability, and (ii) education on health and mortality using a structural equation model suggested by Conti et al. (2010). We extend their model by allowing for a duration dependent variable, and an ordinal educational variable. Data come from a Dutch cohort born between 1937 and 1941, including detailed measures of cognitive ability and family background at age 12 . The data are subsequently linked to the mortality register 1995-2011, such that we observe mortality between ages 55 and 75 . The results suggest that at least half of the unconditional survival differences between educational groups are due to a 'selection effect', primarily on basis of cognitive ability. Conditional survival differences across those having finished just primary school and those entering secondary education are still substantial, and amount to a 4 years gain in life expectancy, on average.

JEL Classification: $\quad$ C41, I14, I24

Keywords: education, cognitive ability, mortality, structural equation model, duration model

Corresponding author:

Govert Bijwaard

Netherlands Interdisciplinary Demographic Institute (NIDI)

PO Box 11650

NL-2502 AR The Hague

The Netherlands

E-mail: bijwaard@nidi.nl

\footnotetext{
* Van Kippersluis gratefully acknowledges funding from the National Institute on Aging (NIA) under grant R01AG037398 and from NETSPAR under the project "Income and health, work and care across the life cycle II". The authors acknowledge access to linked data resources (DO 1995- 2011) by Statistics Netherlands (CBS). We thank Mars Cramer and Mirjam van Praag for help in accessing the original data, and are grateful to Mars Cramer, and attendants from the International Health Economics Association conference in Sydney 2013, the Empirical Health Economics conference in Munich 2013, the Multistate Event History Analysis in Hangzhou, and seminar participants at University of Southern California and Erasmus University Rotterdam, for helpful comments.
} 


\section{Introduction}

Disparities in health and life expectancy across educational groups are striking and pervasive, and are considered one of the most compelling and well established facts in social science research (Mazumder, 2012). Even in an egalitarian country such as the Netherlands, with a very accessible health care system, the difference in life expectancy between the university educated and those who finished only primary school is 6 to 7 years (CBS, 2008). It is commonly assumed that a large part of this association derives from the causal effect of education on health outcomes. An abundant list of possible mechanisms was proposed, among which occupational demands, health behavior, and the ability to process information are the most commonly mentioned (Ross and Wu, 1995; Cutler and Lleras-Muney, 2008).

Yet, the association between education and health could also stem from (i) 'reverse causality', in which childhood ill-health constrains educational attainment (Behrman and Rosenzweig, 2004; Case et al. 2005), and (ii) confounding 'third factors' such as ability, parental background and time preference that influence both education and health outcomes (Fuchs, 1982; Auld and Sidhu, 2005; Deary, 2008).

Studies based on natural experiments in education, such as changes in compulsory schooling laws, overcome the difficulty of separating the direct causal effect of education from third factor effects. The estimates based on these studies point towards a small effect (Lleras-Muney, 2005; Oreopoulos, 2006; Van Kippersluis et al. 2011; Meghir et al. 2012), or even insignificant effect of education on health and mortality (Arendt, 2005; Albouy and Lequien, 2008; Mazumder, 2008; Braakmann, 2011; Clark and Royer, 2013). This suggests that confounding factors may well play an important role in shaping the strong association between education and health.

Surprisingly little research in economics has investigated the contribution of early childhood abilities and childhood social background in shaping the association 
between education and health. ${ }^{1}$ Some recent economic studies report associations between childhood cognitive and non-cognitive abilities, and health outcomes at ages 30-40 using the British Cohort Study (Murasko, 2007), the U.K. National Child Development Study (Carneiro et al. 2007), the U.S. National Longitudinal Study of Youth 1979 (Auld and Sidhu, 2005; Kaestner and Collison, 2011), or the Dutch "Brabant data" (Cramer, 2012). It is established that cognitive ability and some non-cognitive factors such as self-esteem are associated with health outcomes. Nonetheless, hardly anything is known about (i) the relative impact of education and childhood abilities on health outcomes, and in turn (ii) how much of the association between education and health is explained by these cognitive and non-cognitive abilities.

A notable contribution to the literature is a recent series of papers by Conti and Heckman (2010), Conti et al. (2010; 2011), and Heckman et al. (2011) who, using the British Cohort Study and the National Longitudinal Study of Youth (NLSY79), estimate a structural equation model in which the interdependence between education, health, and two latent factors capturing cognitive and non-cognitive abilities is explicitly modeled. The authors show that for most health outcomes around half of the association between education and health is driven by cognitive and non-cognitive abilities and early childhood social background. The other half is interpreted as the causal effect of education on health.

While the series of papers by Conti, Heckman and co-authors provided a significant contribution to the literature, there are two notable limitations. First, the health outcomes are measured at age 30 , an age at which health differences by education may not have fully materialized. In fact, disparities in health and mortality seem to peak around middle-age (Cutler and Lleras-Muney, 2008). Secondly, the health measures are all self-reported, which may bias the estimates since education

\footnotetext{
${ }^{1}$ See Gottfredson (2004) for an overview of the epidemiological literature.
} 
is related to subjective health perceptions (Bago d'Uva et al. 2008).

In this paper we aim to disentangle the effects of education and cognitive ability on health outcomes. We will use the so-called "Brabant data" - a representative cohort of primary school sixth graders in the Dutch province of Noord-Brabant that has detailed information on cognitive ability and social background measured back in 1952. Three follow-up surveys in 1957, 1983 and 1993 contain information on education, employment, and self-reported health. We have linked these data to the mortality register 1995-2011, such that the impact on mortality can be analyzed.

The contribution of this paper is threefold. First, we study the relative impact of cognitive ability and education on mortality, as an objective health indicator. The second contribution is that, in contrast to existing studies that measure health outcomes at ages 30-40, we observe mortality during ages 55-75. Finally, we extend the structural equation model by Conti et al. (2010) by allowing for a duration dependent variable (mortality). ${ }^{2}$

The results show that for most ages, cognitive ability and family social class explain around half of the raw differences in mortality across educational groups. Stated otherwise, education remains important in determining mortality even after controlling for cognitive ability, family social class, and a range of other background variables. The conditional survival differences across educational groups are even remarkable, and amount to a 4-year gain in life expectancy for those entering at

\footnotetext{
${ }^{2}$ Savelyev (2012) developed a similar structural equation model for mortality as ours, yet using a discrete-time hazard model and not taking into account dynamic selection. His study is based on the Terman data, a cohort of individuals with IQ beyond 140. Hence, apart from differences in the model specification, his focus is on an extraordinary sample corresponding to the $99.6^{\text {th }}$ percentile of the intelligence distribution, with very limited variation in cognitive ability. Not surprisingly, as a result he focuses on the effect of higher education whereas we focus on secondary education.
} 
least secondary school compared to those that dropped out after primary school.

This paper is structured as follows. Section 2 presents the Brabant data including the available register data from Statistics Netherlands, section 3 presents the structural equation model that we will use to disentangle the relative contributions of cognitive ability and education on health outcomes. Section 4 presents the results and section 5 discusses them.

\section{Data and descriptive statistics}

The data are from a Dutch cohort born between 1937 and 1941. Very detailed information about individual intelligence, social background and school achievement is available for 5,823 individuals. The survey was held in the spring and summer of 1952 among pupils of the sixth (last) grade of primary schools in the Dutch province of Noord-Brabant, and hence is referred to as the "Brabant data". One-fourth of the province population was sampled; mainly by including every fourth child from the schools' list of pupils. ${ }^{3}$ Hartog (1989) investigated the data and found no reason to doubt randomness. A selective dropout of pupils before participating in the data collection does not exist, as primary school was compulsory and enforcement of school attendance was strict (Dronkers, 2002).

Follow-up surveys took place in 1957, 1983 and $1993 .{ }^{4}$ In 1957 only a sub-sample - those who scored above-average on six tests - of the original cohort was interviewed

\footnotetext{
${ }^{3}$ Some schools had school years beginning in April rather than in September. For these schools, half the pupils of half the schools were included in the sample, which yielded 369 observations on a total of 5,823 (Hartog, 1989).

${ }^{4}$ Mathijsen and Sonnemans (1958), Hartog and Pfann (1985), Van Praag (1992), and Hartog, Jonker and Pfann (2002). The complete questionnaire is included in Van Praag (1992) 'Brabantse zesdeklassers, 1952-2010'.
} 
about the school careers between 1952 and 1957 to particularly investigate school career choices of the most intelligent half of the cohort. In 1983 and 1993 attempts were made to trace all initial respondents of the Brabant-cohort to investigate labour market behavior, with overall response rates of around 45 percent. The sample is reduced to 2,998 individuals who have measurements in 1952 and in either 1983 or 1993, or both. ${ }^{5}$

The Brabant data are subsequently linked to administrative records from Statistics Netherlands. The basis for this linkage is identifying information on ZIP code, date of birth, and sex, provided in 1993 by Dutch municipalities. The administrative records are available since 1995. Because of the two-year discrepancy only 86 percent of the 2,998 individuals could be traced in the municipality register in 1995, leaving us with a working sample of 2,579 individuals. Administrative records include the mortality register and the municipality register for the years 1995-2011 inclusive. The mortality register is used to identify drop out due to death in the follow-up period. Demographics are obtained from the municipality register.

Dependent variables: Our outcome variable is Mortality, which is identified from the mortality register in the period 1995-2011. Given that most pupils are born around 1940, this implies that we follow mortality from age 55 until $75 .{ }^{6}$ In our sample, 409 individuals, or 16 percent, died during the period 1995-2011. Close to 50 percent died from cancer, 25 percent from cardiovascular diseases, and 8 percent from respiratory diseases such as COPD and pneumonia. External causes such as accidents comprise only two percent, as do mental disorders (e.g. dementia), diseases

\footnotetext{
${ }^{5}$ In section 4.3 it is verified that selective attrition does not affect our results.

${ }^{6}$ Of the Dutch population 1940 cohort, only 6.8 percent died between the ages of 12 and $55-$ Human Mortality Database, University of California, Berkeley (USA), and Max Planck Institute for Demographic Research (Germany). Available at www.mortality.org or www.humanmortality.de (data downloaded on July 30, 2012).
} 
of the digestive system (e.g. liver cirrhosis) and diseases of the nervous system (e.g. Parkinson).

Independent variables: Our main independent variable of interest is Education, here defined as the highest level of education attended, in three categories: (1) Lower Education, including those who attended at most (extended) ${ }^{7}$ primary school, (2) Lower Vocational Education, including those who attended at most lower vocational education such as the lower agricultural school or lower polytechnic schools, and (3) At least General Secondary School, including those who attended lower general secondary school, higher general secondary school, and Higher Vocational Education or University. Education is retrieved mainly from the 1983 and 1993survey variables on the highest level of education attended. The maximum of the two defines Education, and where missing we update our educational variable with information from the 1957 survey.

Table 1 presents descriptive statistics and shows that 14 percent did not continue school after primary school forming the Lower Education category, 35 percent only attended Lower Vocational Education, and the other 51 percent attended at least General Secondary School. Figures 1 and 2 show the Kaplan-Meier survival curves separately for the three education categories, and for a binary indicator of education with threshold at Lower Education. It is clear that the largest survival differences are between those with only primary school and those above primary school, and that the difference grows with age to around ten percentage points near age 75 .

Our second independent variable is Cognitive Ability. In the Brabant data there are two separate measurements for cognitive ability, both measured at age 12: (i) the

\footnotetext{
${ }^{7}$ At the time, pupils had to stay in school for at least 8 years, or until they reached the age of 14 . Since regular primary school only consisted of 6 grades, some schools offered an additional 2-year extended primary school ("vglo").
} 
Raven Progressive Matrices Test, and (ii) a Vocabulary test (picking synonyms). ${ }^{8}$ The timing of the intelligence test at age 12 avoids possible reverse causality from education to intelligence (Deary and Johnson, 2010) and allows measuring the clean impact of childhood cognitive ability.

The IQ p.m. ('progressive matrices') test focuses on mathematical ability and is a replication of the British Progressive Matrices test, designed by Raven (1958). It is considered to be a 'pure' measurement of problem solving abilities, as it does not require any linguistic or general knowledge (Dronkers, 2002). Hence, the Raven test is supposed to measure cognitive abilities or analytic intelligence (Carpenter et al. 1990). In this sense, the test can be compared to Spearman's g test (1927). The term g refers to the determinants of the common variance within intelligence tests, being the core issue of intelligence measurement (Carpenter et al. 1990).

Table 1 shows that the ability test designed by Raven has an average of 102, with standard deviation of 13 while the vocabulary test is 101 , on average, with standard deviation 13. The correlation between the Raven test and the vocabulary test is 0.38. This suggests that while there seems to be some overlap between what the two tests measure, they additionally measure some idiosyncratic part of cognitive ability. Therefore, we will use both measurements to build a comprehensive latent factor of cognitive ability. In a robustness check we solely use the Raven test to see

\footnotetext{
${ }^{8}$ The data also contain the so-called LO-IV test, which consists of six sub-tests: regularities in series of numbers, analogies in figures, analogies in words, and similarities between concepts (equal, not-equal, cause). Since the quality of this test has been questioned (Hartog et al. 2002, p. 5) we will not use this test in our analyses. There is also information on grades for specific courses (Dutch language, mathematics (arithmetics), history, physics, geography, health sciences, and traffic), but since these are not clean measures of cognitive ability and are relative to others in one's classroom, we choose not to use these grades.
} 
whether the results differ.

Control variables: Apart from a fairly standard set of demographic control variables such Age, whether Male, and Birth Rank, we also have information about the social and school environment of the individuals. Most of these variables are reported by the School Principal. Family Social Class is measured in three categories from lowest to highest depending on father's occupation. ${ }^{9}$ We additionally know whether the child had to work in the parent's farm or company, defining the binary indicator Child Works.

Available information regarding the school includes School Type and the Number of Teachers. Repeat defines the number of classes that children had to repeat. Further, we know the Teacher's Advice regarding further education of the child, and the Preference of the Parents concerning the education of the pupil, categories of which are defined in Table 1, which also includes descriptive statistics.

We have no information about childhood health status, which prevents us from investigating the possibility of reverse causality from health to education in our sample. The sample is comprised of pupils that made it to the final grade of primary school. Hence, pupils with severe health problems impairing going to school in the first place will not be in our sample. Moreover, in the 1983 wave of the survey male

\footnotetext{
${ }^{9}$ We classify lower administrative, agricultural, industrial, and other lower workers, and the disabled into the Lowest Social Class. If the School Principal considered the family "antisocial", the family is also classified into the Lowest Social Class. Intermediary personnel, self-employed farmers, self-employed craftsmen, and the retired are categorized into the Intermediate Social Class (following Cramer, 2012). Teachers, executives and academics are classified into the Highest Social Class. In case father's occupation is missing, we use father's education for individuals in the 1957 survey. Father's education is classified into 3 levels, which we directly translate into the three social classes. We use mother's education in case the father died or was not present in the household.
} 
respondents were asked whether they served in the military. The main reason for disqualification of compulsory military duty is health problems. ${ }^{10}$ Since the fraction of individuals having served in the military is almost identical across educational levels, this provides some indirect evidence that health differences across educational levels were minimal during teenage years. We furthermore refer to Conti et al. (2010) who showed that in their sample childhood health, as measured by childhood height, was not an important determinant of educational choice. The lack of information on childhood health should therefore not be a major source of concern.

\section{Methodology}

Our empirical approach is an extension of the structural equation framework developed by Conti et al. (2010). It allows a way of modeling the interrelationships between abilities, education and health outcomes. We first present the standard model, after which we will present our two extensions. Finally, we explain how we disentangle the effects of cognitive ability and education on the health outcomes.

\subsection{Basic structural equation model}

The standard model consists of three parts: (i) a binary educational choice depending on latent abilities and other covariates, (ii) potential outcomes depending on the choice of education, latent abilities, and other covariates, and (iii) a measurement system for the latent abilities.

The binary indicator for education $D_{i}$ is defined as 1 if individuals took any

\footnotetext{
${ }^{10}$ Other reasons were exemption owing to one's brother's service, grounds of conscience, or personal indispensability (e.g. Van Schellen and Nieuwbeerta, 2007).
} 
education beyond the compulsory schooling age, and 0 if not:

$$
D_{i}= \begin{cases}1 & \text { if } D_{i}^{*} \geq 0 \\ 0 & \text { otherwise }\end{cases}
$$

where we assume $D_{i}^{*}$ is an underlying latent utility which is continuous and linear, and depends on latent abilities $\theta$, and observed characteristics $X^{D}$ :

$$
D_{i}^{*}=\gamma X_{i}^{D}+\alpha_{D} \theta_{i}+v_{i D}
$$

with $v_{D}$ an error term independent of $X^{D}$ and $\theta$. We assume that $v_{D}$ is normally distributed, which implies that we have a probit model for the educational choice. We fix the variance at 1 since the variance is not identified in a probit model.

The second part is the potential outcomes part, in which there are two potential outcomes $Y_{i 1}$ and $Y_{i 0}$ where the former is the outcome in case the individual chose to pursue education beyond what is compulsory, and the latter is the outcome in case the individual dropped out of school right after the compulsory schooling age. Both $Y_{i 1}$ and $Y_{i 0}$ depend on latent ability $\theta$, and on observed characteristics $X^{Y}$ :

$$
\begin{aligned}
& Y_{i 1}=\beta_{1} X_{i}^{Y}+\alpha_{1} \theta_{i}+\nu_{i 1} \\
& Y_{i 0}=\beta_{0} X_{i}^{Y}+\alpha_{0} \theta_{i}+\nu_{i 0}
\end{aligned}
$$

with $\left(\nu_{0}, \nu_{1}\right)$ independent of $X^{Y}$ and $\theta$, and both follow a normal distribution with variance $\sigma_{1}^{2}$ and $\sigma_{0}^{2}$, respectively.

The final part of the model is the measurement equation, where one or two measurements, $M_{k i}(k=1,2)$, implicitly define the latent ability $\theta$ :

$$
M_{k i}=\delta_{k} X_{i k}^{M}+\alpha_{M_{k}} \theta_{i}+v_{i M_{k}}
$$

with $v_{M_{k}}$ independent of $X^{M}$ and $\theta$. We assume that $v_{M}$ is normally distributed with variance $\sigma_{M}^{2}$. 
Identification of factor models requires normalizations that set the location and scale factors. If a standard normal distribution for the latent ability $\theta$ is assumed, which fix the mean to zero and the variance to one, the model is identified and can be estimated by Maximum Likelihood on basis of Gaussian quadrature approximation or simulation methods.

\subsection{Allowing for a duration dependent variable}

While the basic model is extremely useful in disentangling the relative contributions of education and abilities on continuous and binary health outcomes, the model does not allow for a duration outcome like survival till death.

In our extended model, the first part is the same, defining a binary educational choice as in (1) and (2), placing the cut-off at Lower Education (primary school). Hence, in our model individuals face the choice of quitting after primary education $(D=0)$, or enrolling into secondary education $(D=1)$. The measurement equation for latent ability is defined by (5), where we have two measurements for latent cognitive ability.

For a duration outcome like mortality it is more common to define the potential outcomes in terms of the hazard (or intensity) that the outcome of interest occurs. ${ }^{11}$ The observed hazard is

$$
\lambda\left(t_{i}\right)=\lambda^{(1)}\left(t_{i}\right)^{D_{i}} \cdot \lambda^{(0)}\left(t_{i}\right)^{1-D_{i}}
$$

with $\lambda^{(1)}\left(t_{i}\right)$ being the hazard rate for an individual with education level beyond

\footnotetext{
${ }^{11}$ We can use a duration model with potential outcomes because the endogenous education choice is determined before mortality plays a major role: mortality can be largely ignored for young ages. If the education choice would still play a role during higher mortality rates the model should take dynamic selection into account. Then a 'timing-of-events' model could be a better model, see Abbring and Van den Berg (2003).
} 
primary school $\left(D_{i}=1\right)$, and $\lambda^{(0)}\left(t_{i}\right)$ being the hazard rate for an individual with an education level equal to primary school $\left(D_{i}=0\right)$. We assume a Gompertz proportional hazard model for the two potential hazards, which has been shown to be an accurate representation of mortality between the ages of 30 and 80 (e.g. Gavrilov and Gavrilova, 1991; Cramer, 2012). Both potential hazards depend on the latent ability $\theta,{ }^{12}$ and observed characteristics $X^{Y}$ :

$$
\begin{aligned}
& \lambda^{(0)}\left(t_{i} \mid X^{Y}, \theta\right)=\exp \left(a_{0} t_{i}+\beta_{0} X_{i}^{Y}\left(t_{i}\right)+\alpha_{0} \theta_{i}\right) \\
& \lambda^{(1)}\left(t_{i} \mid X^{Y}, \theta\right)=\exp \left(a_{1} t_{i}+\beta_{1} X_{i}^{Y}\left(t_{i}\right)+\alpha_{1} \theta_{i}\right)
\end{aligned}
$$

The effect of latent ability on the hazard is captured by $\alpha_{0}$ and $\alpha_{1}$. The corresponding potential survival rates are

$$
\begin{aligned}
& S^{(0)}\left(t_{i} \mid X^{Y}, \theta\right)=\exp \left(-\int_{0}^{t} \lambda^{(0)}\left(s_{i} \mid X^{Y}, \theta\right) d s\right) \\
& S^{(1)}\left(t_{i} \mid X^{Y}, \theta\right)=\exp \left(-\int_{0}^{t} \lambda^{(1)}\left(s_{i} \mid X^{Y}, \theta\right) d s\right)
\end{aligned}
$$

An important feature of duration data is that for some individuals we only know that he or she survived up to a certain time (often the end of the observation window). In this case an individual is (right) censored, $\Delta_{i}=0$, and we use the survival function instead of the hazard in the likelihood function. Another feature of duration data is that only individuals are observed having survived up to a certain age. In our case, mortality follow-up is only available from age 55 onwards. In this case the individuals are left-truncated, and we need to condition on survival up to the age of first observation, $t_{i 0}$.

The likelihood contribution of individual $i$ in our duration model is

$$
L_{i}^{(j)}=\lambda^{(j)}\left(t_{i}\right)^{\Delta_{i}} S^{(j)}\left(t_{i}\right) / S^{(j)}\left(t_{i 0}\right), \quad j=0,1
$$

\footnotetext{
${ }^{12}$ The latent ability in the hazard is similar to including unobserved heterogeneity in the hazard and for identification the unobserved heterogeneity need to have a finite mean. The mean of unobserved heterogeneity term in our model, $e^{\alpha \theta}$, only depends on $\alpha$ and is finite when $\alpha$ is finite.
} 
With left-truncated data the distribution of latent ability among the survivors (up to the left-truncation time) changes. When only individuals are observed that have survived until age $t_{i 0}$ the likelihood contribution is

$$
\begin{aligned}
L_{i}=\int\left[\Phi\left(\gamma X_{i}^{D}+\alpha_{D} \theta\right) \cdot \lambda^{(1)}\left(t_{i} \mid X^{Y}, \theta\right)^{\Delta_{i}} S^{(1)}\left(t_{i} \mid X^{Y}, \theta\right) / S^{(1)}\left(t_{i 0} \mid X^{Y}, \theta\right)\right]^{D_{i}} \\
\times\left[\Phi\left(-\gamma X_{i}^{D}-\alpha_{D} \theta\right) \cdot \lambda^{(0)}\left(t_{i} \mid X^{Y}, \theta\right)^{\Delta_{i}} S^{(0)}\left(t_{i} \mid X^{Y}, \theta\right) / S^{(0)}\left(t_{i 0} \mid X^{Y}, \theta\right)\right]^{1-D_{i}} \\
\times \prod_{k=1}^{2} \frac{1}{\sigma_{M_{k}}} \phi\left(\frac{M_{k i}-\delta_{k} X_{k i}^{M}-\alpha_{M_{k}} \theta}{\sigma_{M_{k}}}\right) d H\left(\theta \mid T>t_{i 0}\right)
\end{aligned}
$$

with the distribution of the latent abilities conditional on survival up to $t_{i 0}$

$d H\left(\theta \mid T>t_{i 0}\right)=\frac{\left[\Phi\left(\gamma X_{i}^{D}+\alpha_{D} \theta\right) S^{(1)}\left(t_{i 0} \mid X^{Y}, \theta\right)+\Phi\left(-\gamma X_{i}^{D}-\alpha_{D} \theta\right) S^{(0)}\left(t_{i 0} \mid X^{Y}, \theta\right)\right] h(\theta)}{\int\left[\Phi\left(\gamma X_{i}^{D}+\alpha_{D} \theta\right) S^{(1)}\left(t_{i 0} \mid X^{Y}, \theta\right)+\Phi\left(-\gamma X_{i}^{D}-\alpha_{D} \theta\right) S^{(0)}\left(t_{i 0} \mid X^{Y}, \theta\right)\right] h(\theta) d \theta}$

with $h(\theta)$ is a normal distribution with variance $\sigma_{\theta}^{2}=1$. The maximum likelihood estimation of the parameters involves the calculation of an integral that does not have an analytical solution. However, Gaussian quadrature can approximate this one dimensional integral very well.

\subsection{Allowing for an ordered discrete educational choice}

Usually education is available in more than two categories with a natural ordering of the alternative education levels. We extend the standard model to account for this type of ordinal independent variable, where the starting point is, again, an index model with a single latent variable given as in (2). Assume there are $K$ education levels and define $D_{i}$ as the indicator of education that takes value $k$ if the individual has reached education level $k$ :

$$
D_{i}=k \quad \text { if } \zeta_{k-1}<D_{i}^{*} \leq \zeta_{k}
$$


where $\zeta_{0}=-\infty$ and $\zeta_{K}=\infty$. Then, assuming normally distributed $v_{D}$, we have an ordered probit model with $(K-1)$ additional threshold parameters, $\zeta_{k}$. Each education level now has a corresponding potential Gompertz hazard $\lambda^{(k)}$, that depends on exogenous characteristics $X^{Y}$ and on the unobserved latent ability, i.e.,

$$
\lambda^{(k)}\left(t_{i} \mid X^{Y}, \theta\right)=\exp \left(a_{k} t_{i}+\beta_{k} X_{i}^{Y}\left(t_{i}\right)+\alpha_{k} \theta_{i}\right)
$$

\subsection{Disentangling the effects of ability and education}

The difference in the Kaplan-Meier survival curves is the unconditional survival difference between the two levels of educational attainment, and can be interpreted as the association between education and mortality. Here we are interested to what extent this association is driven by cognitive ability and other control variables. Using the estimated parameters, we define the conditional survival difference between the two levels of educational attainment, where conditioning is on basis of cognitive ability and the other control variables, as follows:

$$
\iint E\left[S^{(1)}(t)-S^{(0)}(t) \mid X=x, \theta=f\right] d F_{X, \theta}(x, f)
$$

where $S^{(1)}(t)$ denotes the survival time up to a age $t$ for individuals with at least secondary education $(D=1), S^{(0)}(t)$ is the survival time up to age $t$ for those with primary school only $(D=0), X$ are the covariates, and $\theta$ is the value of latent cognitive ability. We integrate over the joint distribution of the covariates and latent ability, $F_{X, \theta}(x, f) .{ }^{13}$ Note that these conditional survival differences are conditional on surviving to the initial age, which is 55 in our case.

\footnotetext{
${ }^{13}$ Since the conditional survival differences may well be very different for individuals in different parts of the education distribution, we additionally define the conditional survival difference for those with $D=1$, and for those with $D=0$ as follows:

$$
\iint E\left[Y_{1}(t)-Y_{0}(t) \mid X=x, \theta=f, D=1\right] d F_{X, \theta \mid D=1}(x, f)
$$
}


Unfortunately, the integrals cannot be solved analytically, as the dimension of the covariates $X$ is too large. Hence in order to illustrate the conditional survival differences we resort to simulation. This procedure consists of three steps:

1. We determine the distribution of all included variables - separately for the whole sample, and separately for those with $D=0$ and $D=1$.

2. We draw 10,000 individuals on basis of the empirical distribution of the covariates and compute the conditional hazard rates using the estimated coefficients of equations (7) and (8), conditional on the value of the latent ability.

3. For every conditional hazard rate we determine the unconditional survival function for every age from 55 to 100 on basis of equations (9) and (10), and by integrating out the latent ability through Gaussian quadrature methods.

We repeat these steps 100 times and for each simulation round we draw a vector of parameter estimates assuming that the estimated coefficients are normally distributed around the point estimates with a variance-covariance matrix equal to the estimated one.

With this information, we can compute the fraction of individuals that is still alive at a certain age for the two educational groups (both the average and the variance). This defines the conditional survival difference between the two educational groups, since we condition on cognitive ability and the other covariates. The simulations also allow us to compute life expectancy separately for the two educational groups.

In order to illustrate the relative importance of education and cognitive ability, we decompose the unconditional survival differences from the Kaplan-Meier curves

$$
\iint E\left[Y_{1}(t)-Y_{0}(t) \mid X=x, \theta=f, D=0\right] d F_{X, \theta \mid D=0}(x, f)
$$


in Figures 1 and 2 into the conditional survival difference and a residual, which is a selection effect on basis of cognitive ability and the other factors. Note that this selection effect is the combination of actual selection bias and selection on basis of perceived gains of secondary education.

For the ordinal education measure the procedure is very similar. We have three potential hazards and three possible survival functions, one corresponding to each educational level. Although there are more possibilities now to compare the educational groups, we choose to focus on two binary comparisons of the particular educational level to the educational level directly preceding it. Hence, we estimate two different conditional survival differences: (i) lower vocational education compared to primary education only, and (ii) at least general secondary education compared to lower vocational education.

\section{Results}

Our baseline specification is the survival model with a binary education variable and two measurements for cognitive ability. We estimate the model by maximizing the likelihood in (12), and present the results in section 4.1. Then we generalize the model by allowing for an ordinal educational variable including three levels, results of which are presented in section 4.2.

The set of included observed characteristics does not differ in both cases. Exogenous factors influencing the outcome, $X_{y}$ in (7) and (8), include male, whether the child is working, family social class, and birth rank. Factors additionally influencing the measurements of cognitive ability, $X_{m}$ in (5), include school type and the number of teachers at school. Finally, on top of the exogenous variables affecting the outcome and intelligence, additional factors influencing the educational choice, $X_{d}$ in (2), include the teacher's advice, whether a grade was repeated, and 
the preference of the parents.

\subsection{Binary education variable}

Table 2 contains the parameter estimates of the model. The first column shows that our latent factor of cognitive ability strongly influences the educational choice, as expected. The probability of entering secondary school can be derived from the impact of the latent factor and is already beyond 0.6 for those with the lowest cognitive abilities, and gradually increases towards one for those with the highest cognitive abilities.

Females were less likely to enter secondary school, as are children who had to work in the family business during primary school. Family social class is a strong predictor of education, with children from the higher social classes significantly more likely to enter secondary school. Children who went to protestant or other schools, as compared to those who went to catholic schools, were more likely to enter secondary school. Strong predictors of educational choice are the teacher's advice and the preference of the parents. Children who repeated one or more grades were less likely to enter secondary school.

Interestingly, columns 2 and 3 show that on both measurements of cognitive ability girls did slightly better, and children from higher social classes had higher scores. School characteristics such as the school type and the number of teachers also relate to the test scores.

The final two columns of the table present the determinants of mortality across the two educational groups. While the point estimates of the effect of cognitive ability on mortality are negative as expected, the effects do not reach statistical significance at the 10 percent level, although the p-values are extremely close to the 10 percent cut-off. Males have a higher hazard of dying compared to females, 
although the effect is only statistically significant among the higher educated.

The coefficients in Table 2 allow to compute the conditional survival difference across educational groups, as described in section 3.4. Figure 4 shows these conditional survival differences for all age groups from 55 to 75 years of age. The association between entering secondary school and mortality, after controlling for family background and cognitive ability, is positive and increases with age. The sizes can be interpreted as percentage point differences in the survival probability at a certain age. Hence, around age 70 entering secondary school is associated with a 2 percentage point increase in the survival probability. Note that the confidence intervals are fairly wide, such that the conditional survival differences only reach statistical significance at higher ages.

If we extrapolate the estimated survival functions outside of our observed age window, the simulations allow computing the estimated differences in life expectancy. This provides an alternative summary measure. The life expectancy of those only finishing primary school is 82.86 , compared with 87.15 for those having finished at least secondary school, a difference that is statistically significant. This implies that entering secondary school is associated with an increase of more than 4 years in life expectancy, which is within the bandwidth of the raw survival difference of 5 years across individuals with primary and secondary education. Nonetheless, it has to be acknowledged that this estimate is based upon extrapolation and hence on relatively strong functional form assumptions.

We decompose the unconditional differences in the Kaplan-Meier survival curves from Figure 2 into a conditional difference and a selection effect on basis of cognitive ability and other control variables. ${ }^{14}$ Figure 5 shows that at early ages mortality differentials are mainly due to selection effects, while after age 60 the importance

\footnotetext{
${ }^{14}$ The corresponding graphs using the distribution of $X$ those with $D=1$ and $D=0$ are very similar.
} 
of education increases. For most ages, the selection effect is responsible for around half of the unconditional differences in survival across educational groups.

To gauge the importance of cognitive ability in the selection effect, we additionally ran all models without the latent factor for cognitive ability. The results show that the conditional survival differences are larger in a model without cognitive ability. ${ }^{15}$ This is an indication that cognitive ability plays an important role in the selection effect. It is tempting to decompose the selection effect into a selection due to cognitive ability and a selection on other characteristics. The selection on other characteristics can be computed as the difference between (i) the unconditional difference from the observed Kaplan-Meier survival rate of the two education levels and (ii) the conditional survival difference from the model without cognitive abilities. The selection on cognitive ability can then be easily computed as the difference between the total selection effect and the part of the selection effect attributed to other characteristics. This is illustrated in Figure 6, which shows that cognitive ability explains the largest part of the selection effect, and in fact selection on other factors is even negative between ages 60 and 70 . We have to emphasize, however, that this interpretation should be taken with care, as cognitive ability could be correlated to other control variables in the model, and as such the selection effect may not be additive.

\subsection{Ordinal education}

This section presents the results for a model with an ordinal educational choice, corresponding to levels 1, 2 and 3 in the definition of Education in section 2. We include both measures for cognitive ability, the Raven test as well as the Vocabulary test, to build a comprehensive factor. The coefficient estimates of the exogenous

\footnotetext{
${ }^{15}$ Results are available upon request.
} 
variables are very similar to the ones presented for the binary educational variable, and hence are not presented here. Figure 7 shows the relationship between cognitive ability and the probabilities of entering the three levels of education. For those with the lowest cognitive skills quitting school after primary school $(D=0)$ or entering lower vocational educational $(D=1)$ are the most likely alternatives with each a probability of around 0.4. The likelihood of both choices decreases with a higher level of cognitive ability, with the probability of quitting primary school decreasing sharper than the probability of entering lower vocational education. In contrast, while less than one out of five of those with the lowest cognitive ability enter general secondary education, this probability increases almost linearly towards one with increasing cognitive ability.

Figure 8 presents the conditional survival differences for the three different educational levels. It is clear that there is a large, but insignificant, conditional survival difference between lower vocational school (level 2) and primary school (level 1). At age 75 , those only finishing primary school are around four percentage points more likely to die than those who entered lower vocational school. The conditional survival difference between general secondary school and lower vocational school is practically zero. This clearly indicates that the largest difference is between those having finished primary school and those beyond primary school, such that the dichotomization in the previous subsection seems justified.

The estimated life expectancy of those only having finished primary school is 84.71, compared to 87.76 for those having finished lower vocational school, and 86.99 for those with at least general secondary school. This implies that the conditional survival difference between level 1 on the one hand and level 2 and 3 on the other hand is around 3 years of life expectancy, which is slightly smaller but reasonably close to the differences when using a dichotomous classification of education. It also shows that the conditional survival difference between lower vocational education 
(level 2) and general secondary education (level 3) in terms of life expectancy is negative, but very small.

Finally, if we decompose the unconditional survival differences between the three educational groups into a conditional survival difference and a selection effect, we obtain Figure 9. This graph shows that the conditional survival difference between primary and vocational education is positive and becomes larger than the selection effect from age 70 onwards, in line with the findings of the dichotomous indicator for education. The conditional survival difference between vocational and higher education is negligible.

\subsection{Robustness checks}

While mortality is an objective, and in some sense "the ultimate", health outcome, the influence of education and cognitive ability may differ depending on the health outcome used. In the 1993 wave of our Brabant survey, hence around age 53 for our sample, a subjective assessment of one's health was asked to the respondents in five categories, i.e. "poor", "sometimes good, sometimes bad", "fair", "good", and "very good". We estimated the model described in section 3, now allowing for an ordinal dependent variable variable, to check robustness to our main outcome measure, and to compare our results to the literature. ${ }^{16}$

We estimated the conditional difference in the probability to report any of the five categories between the two educational groups. In the model using the binary educational variable, the conditional difference in the probabilities for the categories "poor" and "sometimes good, sometimes bad" are -0.03 and -0.08 respectively. The conditional difference in the probabilities for the categories "fair" and "very good"

\footnotetext{
${ }^{16}$ All results not presented and the details of the models used in this section are available upon request.
} 
are very close to zero, while the conditional difference in the probability of reporting to be in "good" health between those having finished only primary school and those entering secondary education is large and amounts to a 15 percentage points increase.

When comparing our results to the literature, we confirm the findings of Hartog and Oosterbeek (1998) that both education and cognitive ability affect self-reported health. Conti and Heckman (2010) used a binary indicator for "poor health" and found that half of the raw differences in poor health is due to a treatment effect of education and the other half was selection. We found that education plays a large role in explaining the raw differences in health levels in a model with five health levels and binary education, see Figure 10.

Since the sample size is somewhat small we chose not to present all results separately by gender. Yet, since both educational choices and survival are obviously dependent on gender, we ran all models separately for males and females. While survival is larger for females, strong disparities in survival across educational groups exist for both males and females. The conditional survival differences are slightly larger for females than for males. However, the relative importance of education, derived from the decomposition of the raw survival differences, is higher for males.

Even though the initial sample in 1952 was found to be representative for the Dutch population at that time, more than half of the sample is lost between 1952 and our observation period that starts in 1995. This could lead to an attrition bias, if attrition is non-random. Unfortunately, we do not have access to the original data files such that we cannot investigate attrition directly. However, Hartog (1989) investigated the non-response for the 1983 survey and found no attrition bias in a wage analysis. ${ }^{17}$ Since the sample in 1983 has been shown to be representative, we

\footnotetext{
${ }^{17}$ Following Hartog, (1989) we investigated whether the attrition between 1993 and 1995 was related to observed characteristics. Literally all explanatory variables including education, family background, and intelligence were not related to attrition. The only exception was self-reported
} 
reran all analyses on just the respondents that were observed in 1983 and found no substantial changes in the results. This suggests that selective attrition does not affect our results.

One could argue that the Raven progressive matrices test is a purer measurement of cognitive ability and should be used independently from the vocabulary test. We ran all analyses for both the binary and ordinal educational classification using only the Raven test as a measure of cognitive ability, and the results were very similar.

We additionally varied the observed characteristics in the model. First by including additional variables among the exogenous variables such as family size, number of children, additional school characteristics (e.g. whether restricted to girls, restricted to boys, or mixed), and whether both parents were still alive. These variables were not statistically significant in any of the models, and did not alter the results. Second, we also checked robustness to excluding individuals with item nonresponse on some of the observed characteristics. When excluding individuals with item non-response the results remain similar.

\section{Discussion}

This paper estimates to what extent survival differences across educational groups are due to a 'selection effect' on basis of cognitive ability and other background variables. We extend the structural equation model of Conti et al. (2010) to allow for a duration dependent variable and an ordinal educational choice, and estimate the model on basis of a Dutch cohort born around 1940 observed between ages 55 and 75. Most important conclusion is that the selection effect on basis of cognitive ability is responsible for around half of the raw differences in survival. Yet, even conditional on cognitive ability and a wide range of individual characteristics, survival differences health; a worse health status increased the probability of attrition between 1993 and 1995 . 
between individuals having finished only primary school and those that entered at least secondary education are still substantial, and correspond to a 4 year difference in life expectancy.

Even though we analyze mortality between ages 55 and 75 rather than selfreported health at age 30, our findings are in line with the results presented by Conti et al. (2010). Due to this striking similarity in findings, irrespective of the health measures and samples used, two tentative conclusions regarding the education-health gradient are emerging. First, at least half of the raw association between education and health is due to confounding 'third factors', of which cognitive ability proved very important in our analysis, while Conti et al. (2010) and Savelyev (2012) stress the importance of non-cognitive factors, in particular conscientiousness. Second, even after controlling for cognitive ability, family social class, and a range of other background variables, education remains important in determining mortality. This suggests that at least part of the educational differences in health outcomes is due to a genuine, causal effect of education on health.

A limitation of our data is the absence of direct measurements of non-cognitive ability. Hence, we cannot rule out that specific non-cognitive factors influence both education and health, such that our 'conditional survival difference' across educational groups cannot be interpreted as - and is likely to be an upper bound to the causal effect of education on mortality. Moreover, we may overestimate the influence of cognitive ability if correlated non-cognitive abilities are omitted from the model. $^{18}$

We do however observe the teacher's advice regarding secondary education of the child, which presumably is a function of both the cognitive and non-cognitive abilities of the pupil. Hence, one could argue that while controlling for cognitive ability,

\footnotetext{
${ }^{18}$ Although the literature suggests that most non-cognitive abilities are uncorrelated with IQ (Borghans et al. 2011; Savelyev, 2012).
} 
the teacher's advice could be a proxy for non-cognitive abilities. When allowing the teacher's advice to influence mortality directly, on top of being a determinant of educational choice, our results are similar. This gives some comfort in claiming that the lack of a direct measurement of non-cognitive ability does not alter our main conclusions.

A fruitful avenue for future research would be investigating the effect of education on health outcomes using a more elaborate set of non-cognitive abilities. In doing so, the literature could benefit from our structural equation model that allows for a duration dependent variable like mortality, and an ordinal independent variable such as educational attainment. 


\section{References}

Abbring, Jaap, and Gerard van den Berg. 2003. "The Nonparametric Identification of Treatment Effects in Duration Models." Econometrica 71(5): 1491-1517.

Albouy, Valerie, and Laurent Lequien. 2008. "Does compulsory education lower mortality?" Journal of Health Economics 28(1): 155-168.

Arendt, Jacob Nielsen. 2005. "Does Education Cause Better Health? A Panel Data Analysis Using School Reforms for Identification." Economics of Education Review 24(2): 149-60.

Auld, M. Christopher, and Nirmal Sidhu. 2005. "Schooling, Cognitive Ability and Health." Health Economics 14(10): 1019-1034.

Bago d'Uva, Teresa, Owen O'Donnell, and Eddy van Doorslaer. 2008. "Differential health reporting by education level and its impact on the measurement of health inequalities among older Europeans." International Journal of Epidemiology 37(6): $1375-1383$.

Borghans, Lex, Bart H.H. Golsteyn, James J. Heckman, and John E. Humphries. 2011. "IQ, Achievement, and Personality." Unpublished manuscript, University of Maastricht.

Braakmann, Nils. 2011. "The causal relationship between education, health and health related behaviour: Evidence from a natural experiment in England." Journal of Health Economics 30(4): 753-763. 
Carneiro, Pedro, Claire Crawford, and Alissa Goodman. 2007. "The Impact of Early Cognitive and Non-Cognitive Skills on Later Outcomes." CEE DP 92.

Carpenter, Patricia A., Marcel A. Just, and Peter Shell. 1990. "What one intelligence test measures: a theoretical account of processing in the Raven Progressive Matrices Test." Psychological Review 97(3): 404-431.

Case Anne, Angela Fertig, and Christine Paxson. 2005. "The lasting impact of childhood health and circumstance" Journal of Health Economics 24(2): 365-389.

Centraal Bureau voor de Statistiek, CBS. 2008. "Hoogopgeleiden leven lang en gezond" in: Gezondheid en zorg in cijfers 2008, CBS.

Clark, Damon, and Heather Royer. 2013. "The Effect of Education on Adult Mortality and Health: Evidence from Britain." American Economic Review, forthcoming.

Conti, Gabriella, James J. Heckman. 2010. "Understanding the Early Origins of the Education-Health Gradient: A Framework That Can Also Be Applied to Analyze Gene-Environment Interactions." Perspectives on Psychological Science 5(5): 585-605.

Conti, Gabriella, James J. Heckman, and Sergio Urzua. 2010. "The EducationHealth Gradient." American Economic Review Papers and Proceedings 100: 234238. 
Conti, Gabriella, James J. Heckman, and Sergio Urzua. 2011. "Early Endowments, Education, and Health." Unpublished manuscript, University of Chicago, Department of Economics.

Cramer, Jan S. 2012. "Childhood Intelligence and Adult Mortality, and the Role of Socio-Economic Status.” Tinbergen Institute Discussion Paper 2012-070/4.

Cutler, David, and Adriana Lleras-Muney. 2008. "Education and Health: Evaluating Theories and Evidence." In: House James S, Schoeni Robert F, Kaplan George A, Pollack Harold., editors. Making Americans Healthier: Social and Economic Policy as Health Policy. New York: Russell Sage Foundation.

Deary, Ian. 2008. "Why do intelligent people live longer?" Nature 456: 175-176.

Deary, Ian, and Wendy Johnson. 2010. "Intelligence and education: causal perceptions drive analytic processes and therefore conclusions." International Journal of Epidemiology 39: 1362-1369.

Dronkers, Jaap. 2002. "Bestaat er een samenhang tussen echtscheiding en intelligentie?", Mens $\&$ Maatschappij 77(1): 25-42.

Fuchs, Viktor R. 1982. "Time Preference and Health: An Exploratory Study.", in V. Fuchs (ed.) Economic Aspects of Health (Chicago: The University of Chicago Press).

Gavrilov, Leonid A., and Natalia S. Gavrilova. 1991. The Biology of Life Span: A Quantitative Approach. New York: Harwood Academic Publisher, ISBN 3-7186- 
4983-7.

Gottfredson, Linda. 2004. "Intelligence: is the Epidemiologists' elusive "Fundamental Cause" of Social Class Inequalities in Health?" Journal of Personality and Social Psychology 86(1): 174-199.

Hartog, Joop. 1989. "Survey non-response in relation to ability and family background: structure and effects on estimated earnings functions." Applied Economics 21: $387-395$.

Hartog, Joop, and Gerard Pfann. 1985. Vervolgonderzoek Noord-Brabantse zesdeklassers 1983, Verantwoording van hernieuwde gegevensverzameling onder Noordbrabantse zesdeklassers van 1952, Amsterdam: University of Amsterdam.

Hartog, Joop, and Hessel Oosterbeek. 1998. "Health, wealth and happiness: why pursue a higher education? Economics of Education Review, 17(3): 245-256.

Hartog, Joop, Nicole Jonker, and Gerard Pfann. 2002. "Documentatie Brabant data", Amsterdam: Netherlands Institute for Scientific Information Services.

Heckman, James J., John E. Humphries, Sergio Urzua, and Gregory Veramendi. 2011. "The Effects of Educational Choices on Labor Market, Health, and Social Outcomes", Working paper 2011-002, University of Chicago, Department of Economics.

Kaestner, Robert, and Kevin Callison. 2011. "Adolescent Cognitive and NonCognitive correlates of Health." Journal of Human Capital 5(1): 29-69. 
Lleras-Muney, Adriana. 2005. "The Relationship Between Education and Adult Mortality in the United States." Review of Economic Studies 72: 189-221.

Mathijssen, Mathias A.J.M., and G.J.M. Sonnemans. 1958. "Schoolkeuze en schoolsucces bij VHMO en ULO in Noord-Brabant", Tilburg: Zwijssen.

Mazumder, Bhaskar. 2008. "Does Education Improve Health: A Reexamination of the Evidence from Compulsory Schooling Laws." Economic Perspectives 33(2).

Mazumder, Bhaskar. 2012. "The Effects of Education on Health and Mortality" Nordic Economic Policy Review 2012: 261-301.

Meghir, Costas, Martin Palme, and Emilia Simeonova. 2012. "Education, health and mortality: Evidence from a social experiment." NBER Working Paper 17932.

Murasko, Jason E. 2007. "A lifecourse study on education and health: The relationship between childhood psychosocial resources and outcomes in adolescence and young adulthood" Social Science Research 36(4): 1348-1370.

Oreopoulos, Philip. 2006. "Estimating Average and Local Average Treatment Effects of Education when Compulsory School Laws Really Matter" American Economic Review 96(1): 152-175.

Raven, John C. 1958. Mill Hill Vocabulav Scale, 2nd ed. London: H. K. Lewis.

Ross, Catherine E., and Chia-ling Wu. 1995. "The links between education and 
health" American Sociological Review 60(5): 719-745.

Savelyev, Peter A. 2012. "Conscientiousness, Education, and Longevity of HighAbility Individuals", Unpublished manuscript, Vanderbilt University, Department of Economics.

Spearman, Charles. 1927. The Abilities of Man: Their Nature and Measurement. New York: Macmillan.

Van Kippersluis, Hans, Owen O’Donnell, and Eddy van Doorslaer. 2011. "Long Run Returns to Education: Does Schooling lead to an Extended Old Age?" Journal of Human Resources 46(4): 695-721.

Van Praag, Mirjam. 1992. "Zomaar een dataset: 'Noordbrabantse zesde klassers', Een presentatie van 15 jaar onderzoek" Amsterdam: University of Amsterdam.

Van Schellen, Marieke, and Paul Nieuwbeerta. 2007. "De invloed van de militaire dienstplicht op de ontwikkeling van crimineel gedrag." Mens $\&$ Maatschappij 82(1): $5-27$. 


\section{Tables}

Table 1: Descriptive Statistics of the Brabant Data sample

\begin{tabular}{|c|c|c|c|}
\hline Variable & Average & Standard Deviation & Number of Observations \\
\hline \multicolumn{4}{|l|}{ Dependent Variables } \\
\hline Mortality & 0.16 & 0.35 & 2,579 \\
\hline \multicolumn{4}{|l|}{ Independent Variables } \\
\hline \multicolumn{4}{|l|}{ Education } \\
\hline Lower Education & 0.14 & 0.34 & 2,537 \\
\hline Lower Vocational Education & 0.34 & 0.48 & 2,537 \\
\hline At least General Secondary School & 0.51 & 0.35 & 2,537 \\
\hline Raven p.m. test & 102.04 & 13.28 & 2,579 \\
\hline Vocabulary test & 101.42 & 12.87 & 2,579 \\
\hline \multicolumn{4}{|l|}{ Control Variables } \\
\hline Male & 0.58 & 0.49 & 2,579 \\
\hline Birth Rank & 2.50 & 2.55 & 2,412 \\
\hline \multicolumn{4}{|l|}{ Family Social Class } \\
\hline Lowest Social Class & 0.53 & 0.50 & 2,409 \\
\hline Middle Social Class & 0.44 & 0.50 & 2,409 \\
\hline Highest Social Class & 0.03 & 0.16 & 2,409 \\
\hline Child Works & 0.28 & 0.45 & 2,256 \\
\hline \multicolumn{4}{|l|}{ School Religion } \\
\hline Roman-Catholic & 0.76 & 0.43 & 2,518 \\
\hline Protestant & 0.19 & 0.40 & 2,518 \\
\hline Special & 0.03 & 0.17 & 2,518 \\
\hline Public & 0.02 & 0.13 & 2,518 \\
\hline Number of Teachers & 6.92 & 2.47 & 2,452 \\
\hline \multicolumn{4}{|l|}{ Repeat } \\
\hline No Repetition of Grade & 0.64 & 0.48 & 2,462 \\
\hline Repeated Once & 0.27 & 0.45 & 2,462 \\
\hline Repeated Twice or More & 0.09 & 0.28 & 2,462 \\
\hline \multicolumn{4}{|l|}{ Teacher's Advice } \\
\hline Continue Primary School & 0.24 & 0.43 & 2,429 \\
\hline Lower Vocational Education & 0.38 & 0.48 & 2,429 \\
\hline Lower Secondary Education & 0.24 & 0.43 & 2,429 \\
\hline Higher Secondary Education & 0.14 & 0.20 & 2,429 \\
\hline \multicolumn{4}{|l|}{ Preference of the Parents } \\
\hline Work in Family Company & 0.13 & 0.33 & 2,200 \\
\hline Paid Work without Vocational Education & 0.20 & 0.28 & 2,200 \\
\hline Paid Work with Vocational Education & 0.27 & 0.44 & 2,200 \\
\hline General Secondary Education & 0.41 & 0.49 & 2,200 \\
\hline
\end{tabular}

Notes: Author's calculations on basis of the Brabant Data linked to the municipality register and the mortality register. 
Table 2: Duration model - Binary education variable, two measurements for ability

\begin{tabular}{|c|c|c|c|c|c|}
\hline Outcome & $\begin{array}{c}\text { Education } \\
D\end{array}$ & $\begin{array}{c}\text { Raven Test } \\
M_{1}\end{array}$ & $\begin{array}{c}\text { Vocabulary Test } \\
M_{2}\end{array}$ & $\begin{array}{c}\text { Hazard } \\
\lambda^{(0)}\end{array}$ & $\begin{array}{c}\text { Hazard } \\
\lambda^{(1)}\end{array}$ \\
\hline $\begin{array}{l}\text { Cognitive Ability } \\
\alpha\end{array}$ & $0.36^{* * *}$ & $9.63^{* * *}$ & $10.37^{* * *}$ & -0.33 & -0.20 \\
\hline $\begin{array}{l}\text { Constant term } \\
c \\
a\end{array}$ & $2.13^{* * *}$ & $3.59^{* * *}$ & $4.69^{* * *}$ & $\begin{array}{r}-11.68^{* * *} \\
0.11^{* * *}\end{array}$ & $\begin{array}{r}-10.71^{* * *} \\
0.09^{* * *}\end{array}$ \\
\hline $\begin{array}{l}\text { Control variables } \\
\text { Male } \\
\text { Child is working - base is "No" }\end{array}$ & $-0.25^{* * *}$ & $-0.93^{*}$ & $-0.87^{*}$ & 0.33 & $0.66^{* * *}$ \\
\hline $\begin{array}{l}\text { Yes } \\
\text { Missing }\end{array}$ & $\begin{array}{l}-0.29^{* * *} \\
-0.32^{* * *}\end{array}$ & $\begin{array}{l}-3.84^{* * *} \\
-1.07\end{array}$ & $\begin{array}{r}-7.14^{* * *} \\
2.52^{* * *}\end{array}$ & $\begin{array}{r}0.34 \\
-0.87\end{array}$ & $\begin{array}{l}0.15 \\
0.12\end{array}$ \\
\hline $\begin{array}{l}\text { Family social class - base is "Low" } \\
\text { Middle } \\
\text { High } \\
\text { Missing }\end{array}$ & $\begin{aligned} & 0.42^{* * *} \\
& 0.42^{* * *} \\
- & 0.54^{* *}\end{aligned}$ & $\begin{array}{r}2.55^{* * *} \\
4.16^{* * *} \\
-4.39^{* * *}\end{array}$ & $\begin{array}{r}2.24^{* * *} \\
4.68^{* * *} \\
-7.63^{* * *}\end{array}$ & $\begin{array}{l}-0.34 \\
-0.34 \\
-0.67\end{array}$ & $\begin{array}{l}0.00 \\
0.44 \\
0.17\end{array}$ \\
\hline $\begin{array}{l}\text { Birthrank - base is "First" } \\
\text { Second } \\
\text { Third or Fourth } \\
\text { Fifth or higher } \\
\text { Missing }\end{array}$ & $\begin{array}{r}-0.15 \\
-0.09 \\
-0.09 \\
0.11\end{array}$ & $\begin{array}{l}\quad 0.53 \\
-0.22 \\
-3.02^{* * *} \\
-0.63\end{array}$ & $\begin{array}{l}-0.02 \\
-2.70^{* * *} \\
-4.52^{* * *} \\
0.47\end{array}$ & $\begin{array}{r}-0.17 \\
0.09 \\
0.09 \\
1.13^{*}\end{array}$ & $\begin{array}{l}-0.00 \\
-0.19 \\
-0.26^{*} \\
-0.65^{*}\end{array}$ \\
\hline $\begin{array}{l}\text { School religion - base is "Catholic" } \\
\text { Protestant } \\
\text { Other }\end{array}$ & $\begin{array}{l}0.31^{* * *} \\
0.42^{* *}\end{array}$ & $\begin{array}{l}0.62 \\
5.19^{* * *}\end{array}$ & $\begin{array}{l}2.59^{* * *} \\
7.32^{* * *}\end{array}$ & & \\
\hline $\begin{array}{l}\text { Number of teachers - base is " } 5-8 \mathrm{t} \\
\quad \leq 4 \\
9-12 \\
\text { Missing }\end{array}$ & $\begin{array}{r}\text { chers" } \\
-0.16 \\
0.05 \\
0.33\end{array}$ & $\begin{array}{l}-3.81^{* * *} \\
0.37 \\
0.81\end{array}$ & $\begin{array}{l}-3.16^{* * *} \\
0.42 \\
0.66\end{array}$ & & \\
\hline $\begin{array}{l}\text { Teacher's advice - base is "Lower v } \\
\text { Continued primary school } \\
\text { Lower general secondary school } \\
\text { Higher general secondary school } \\
\text { Missing }\end{array}$ & $\begin{array}{l}\text { cational sch } \\
-0.22^{* *} \\
0.42^{* *} \\
0.39 \\
-0.56^{* *}\end{array}$ & & & & \\
\hline $\begin{array}{l}\text { Repeat grade - base is "None" } \\
\text { Once } \\
\text { Twice or more } \\
\text { Missing }\end{array}$ & $\begin{array}{l}-0.30^{* * *} \\
-0.74^{* * *} \\
0.74^{*}\end{array}$ & & & & \\
\hline $\begin{array}{l}\text { Preference of the parents - base is } \\
\text { Work in own company } \\
\text { Work without education } \\
\text { Work with education } \\
\text { General secondary school } \\
\text { Missing }\end{array}$ & $\begin{array}{l}\text { Dnly vocatic } \\
-0.78^{* * *} \\
-1.29^{* * *} \\
-0.88^{* * *} \\
-0.28 \\
-0.85^{* * *}\end{array}$ & lal education & & & \\
\hline
\end{tabular}

Notes: Author's calculations on basis of the Brabant Data linked to the municipality register and the mortality register. 


\section{Figures}

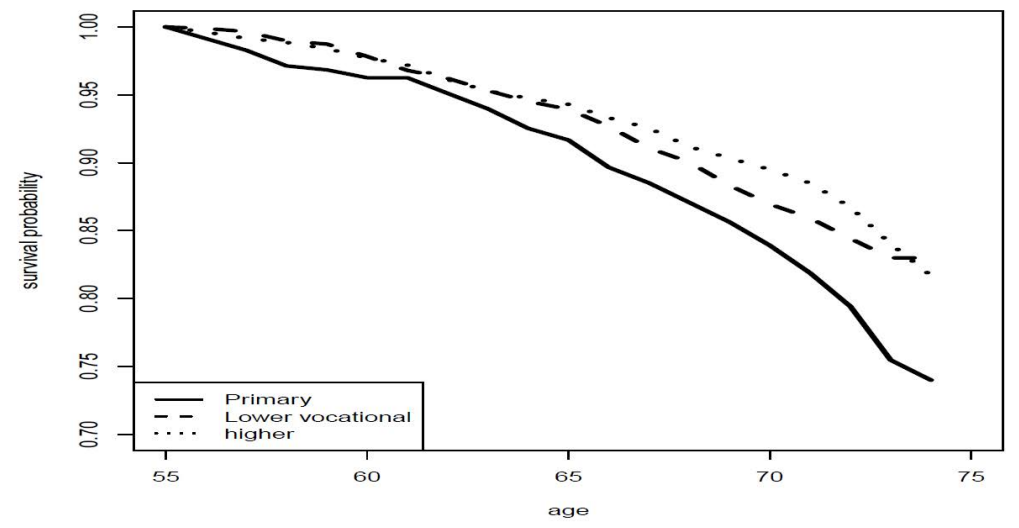

Figure 1: Kaplan-Meier Survival function by education level in three categories

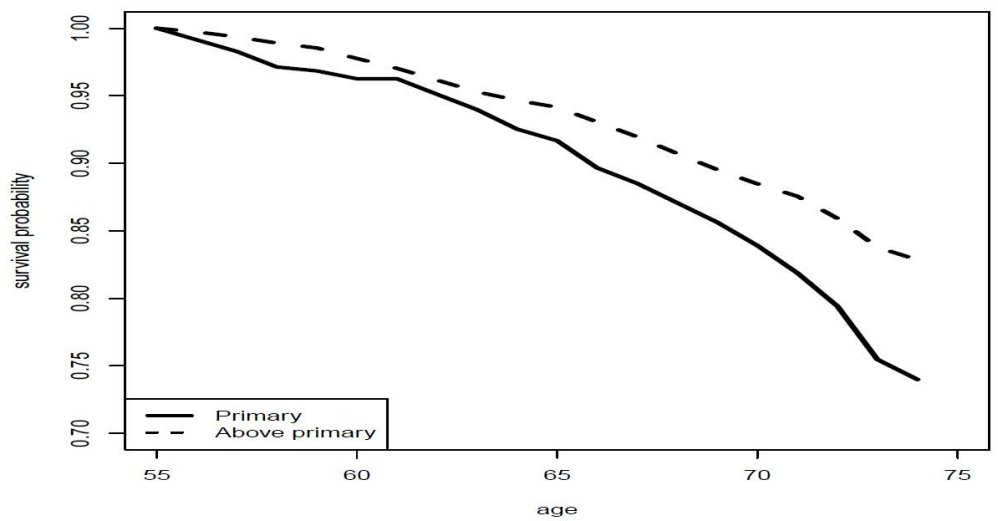

Figure 2: Kaplan-Meier Survival function by education level in two categories 


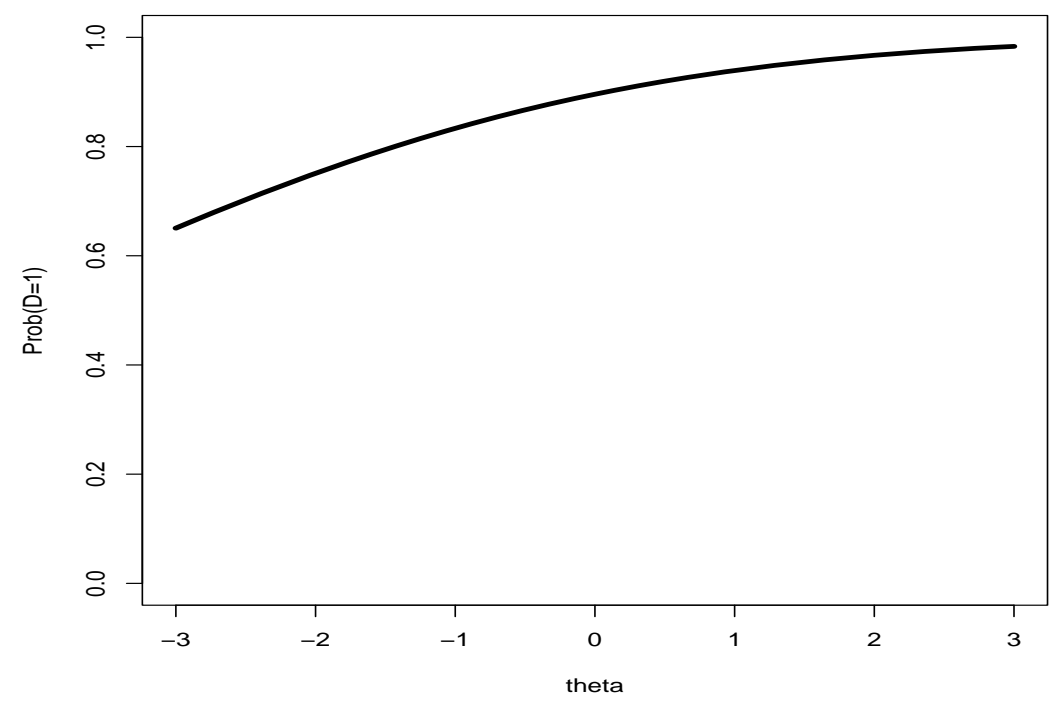

Figure 3: Relationship between cognitive ability and the binary measure for education. 


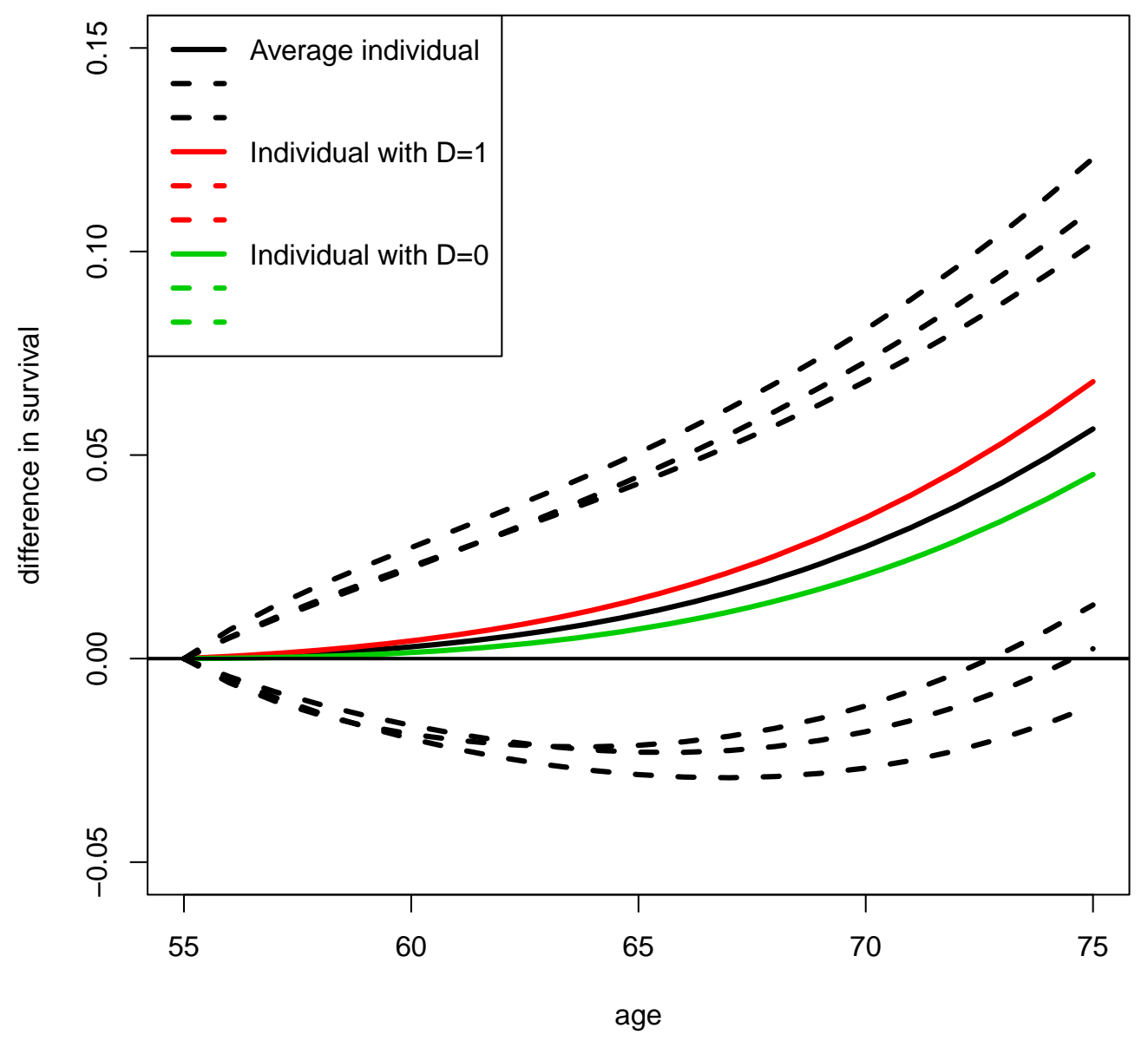

Figure 4: Conditional survival differences by age, binary education variable, two measurements for cognitive ability. Dashed lines indicate the 90 percent confidence intervals. 


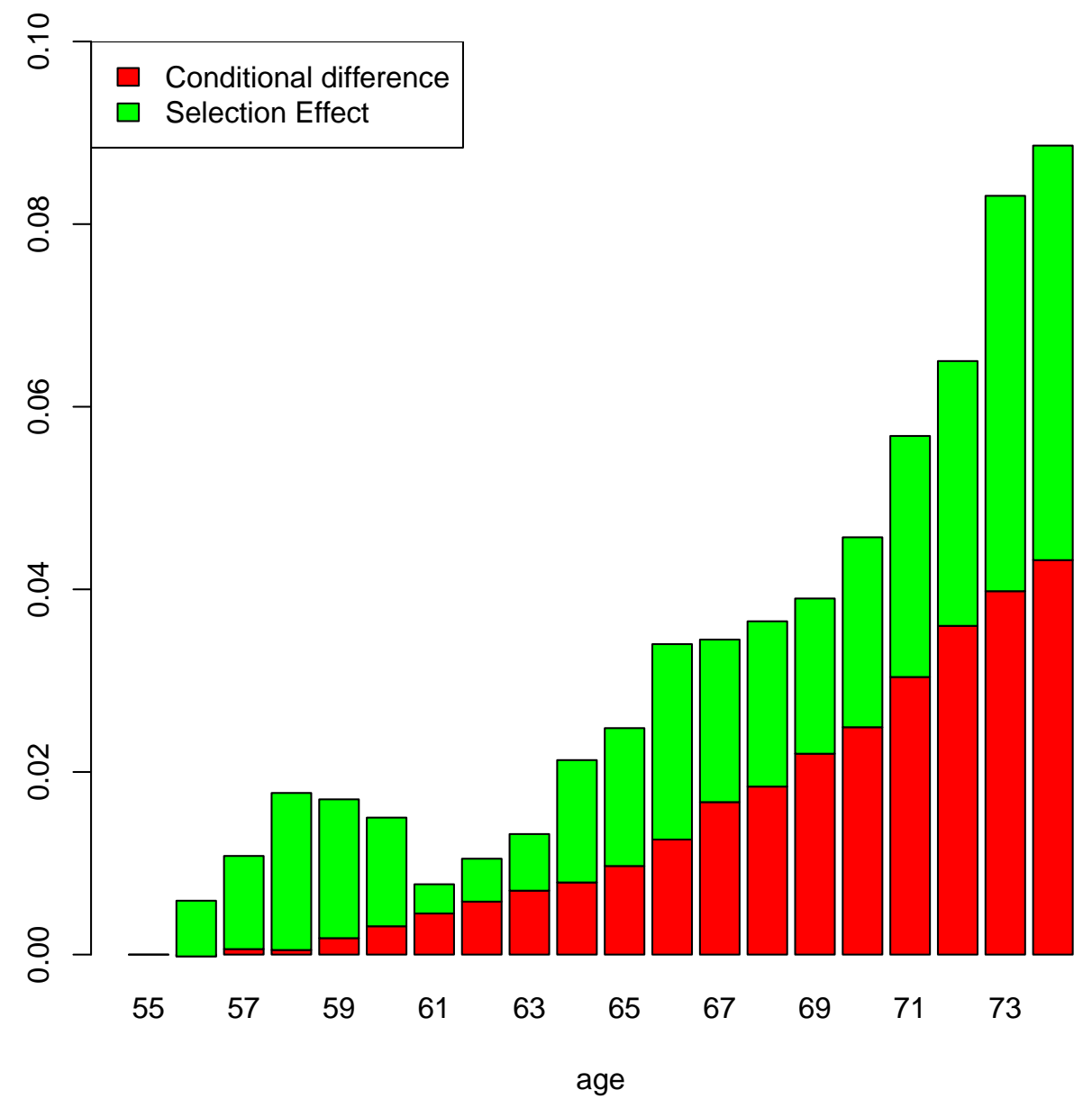

Figure 5: Decomposition of unconditional difference in the Kaplan-Meier Survival function into conditional differences and a selection effect, with binary education variable and two measurements for cognitive ability 


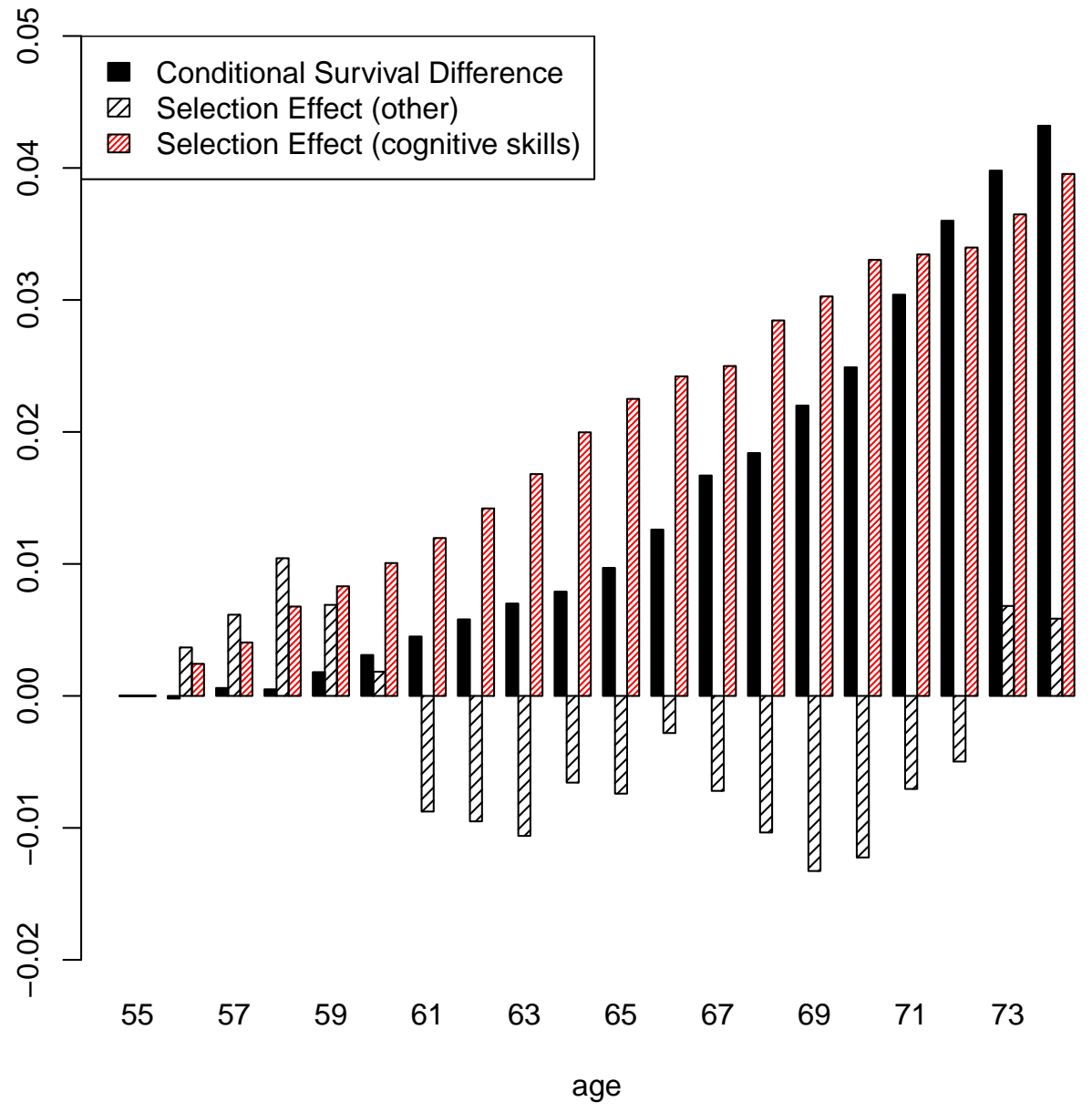

Figure 6: Decomposition of observed difference in the Kaplan-Meier Survival function into conditional differences and a selection effect due to cognitive abilities and other selection effects, with binary education variable and two measurements for cognitive ability 


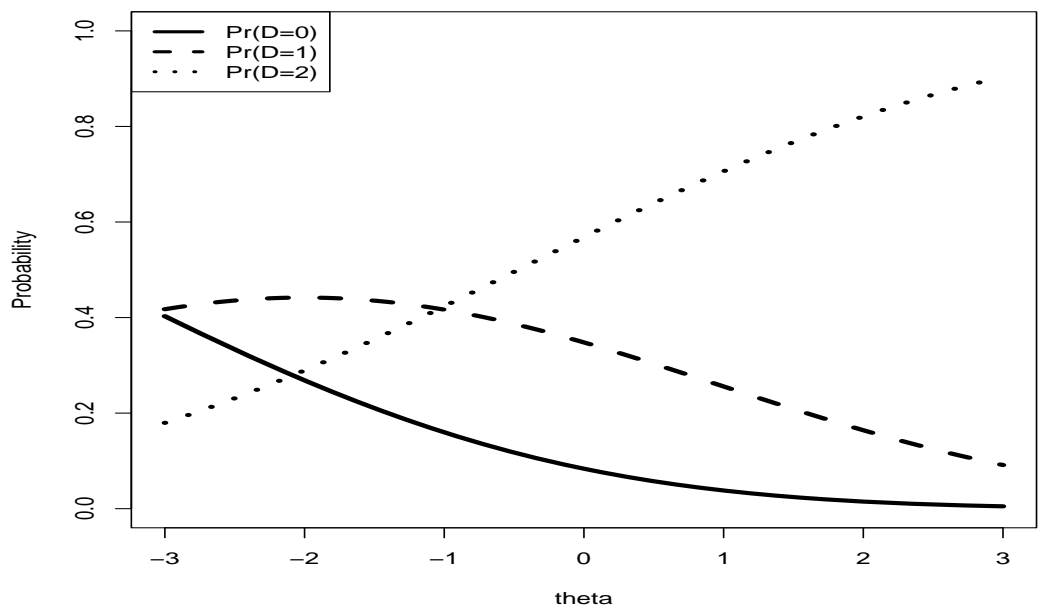

Figure 7: Relationship between cognitive ability and the ordinal measure for education. 


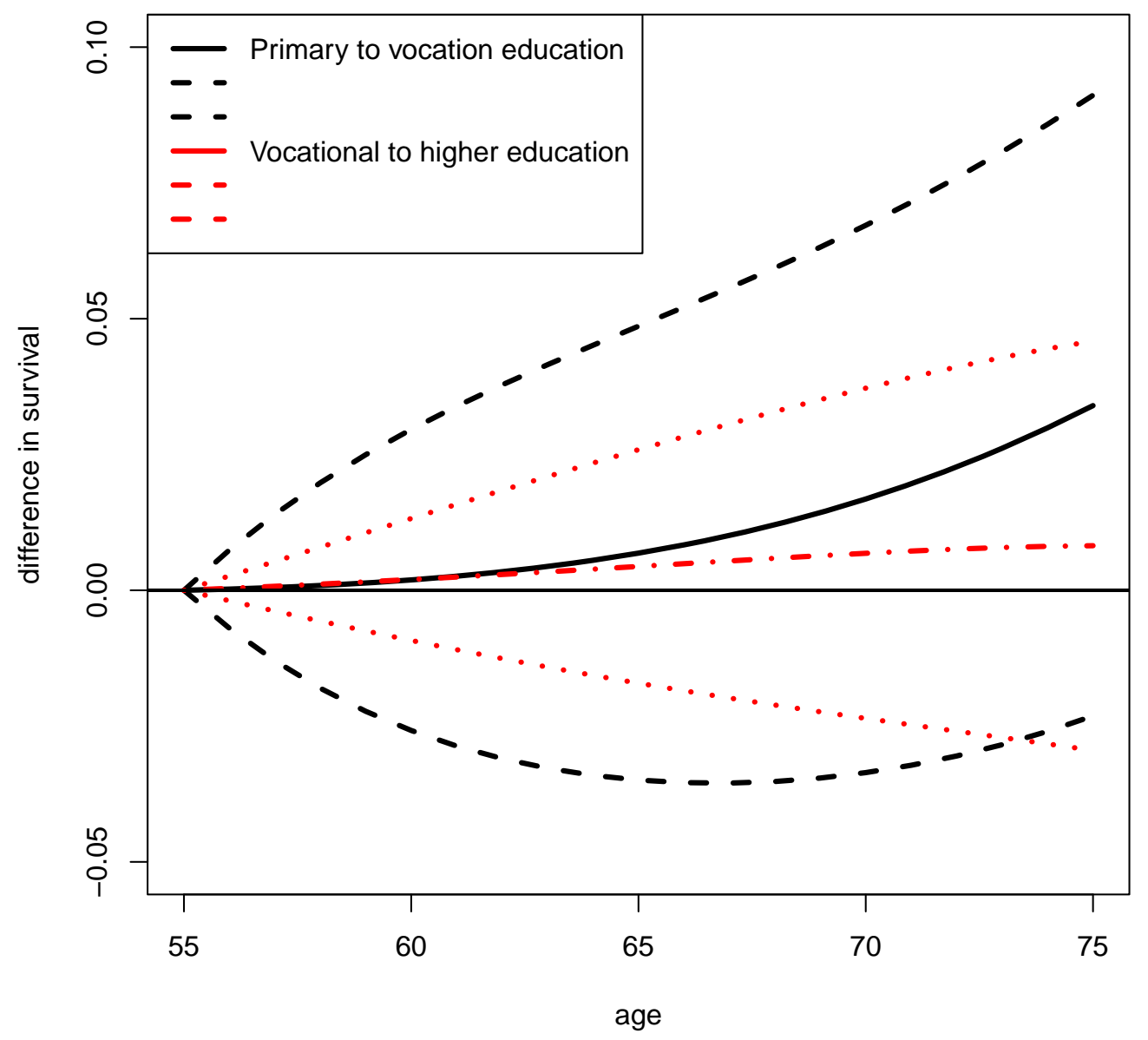

Figure 8: Conditional survival differences by age, ordinal education variable, two measurements for cognitive ability. Dashed lines indicate the 90 percent confidence intervals. 


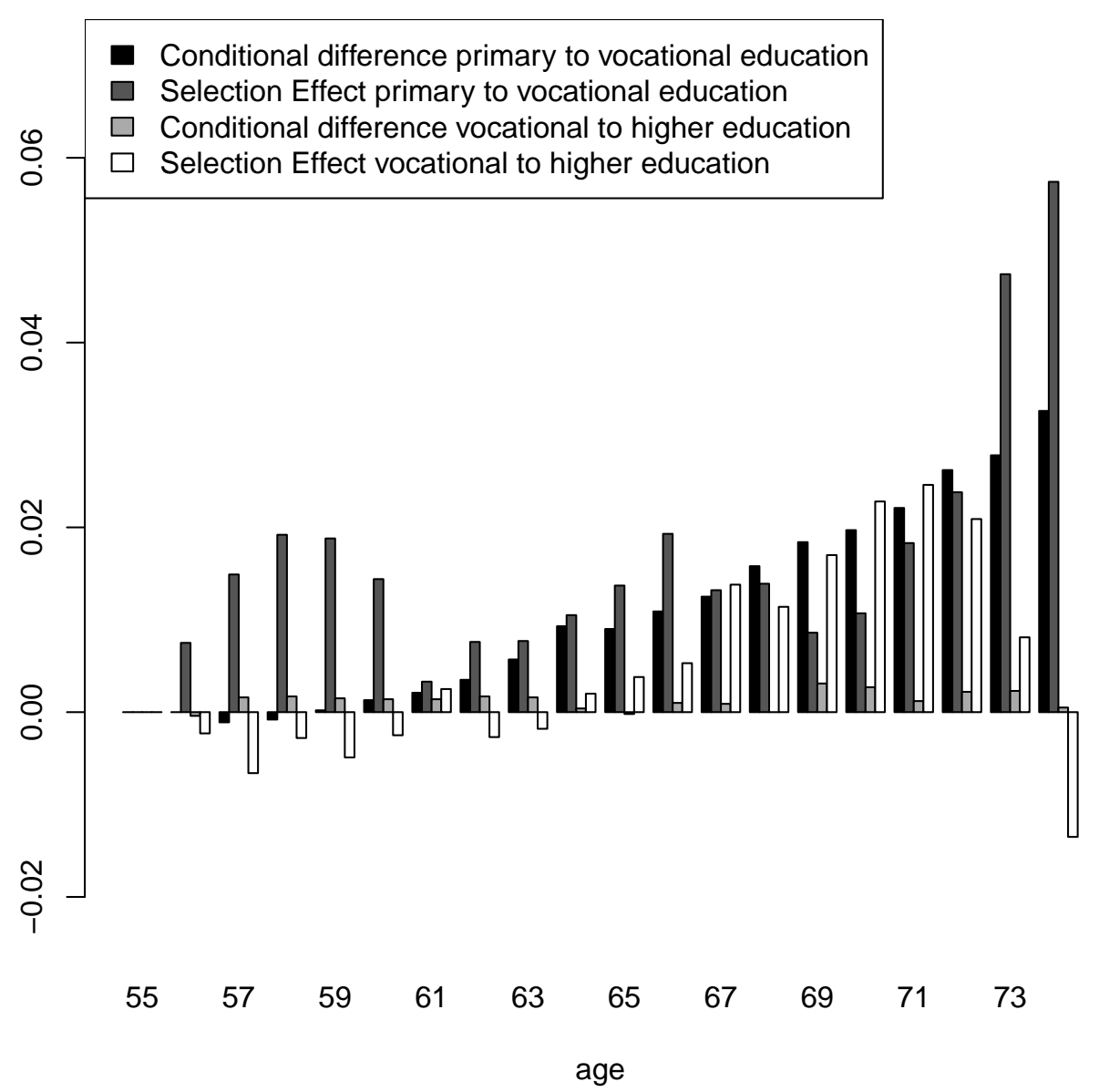

Figure 9: Decomposition of observed difference in the Kaplan-Meier Survival function into conditional differences and a selection effect, with ordinal education variable and two measurements for cognitive ability 


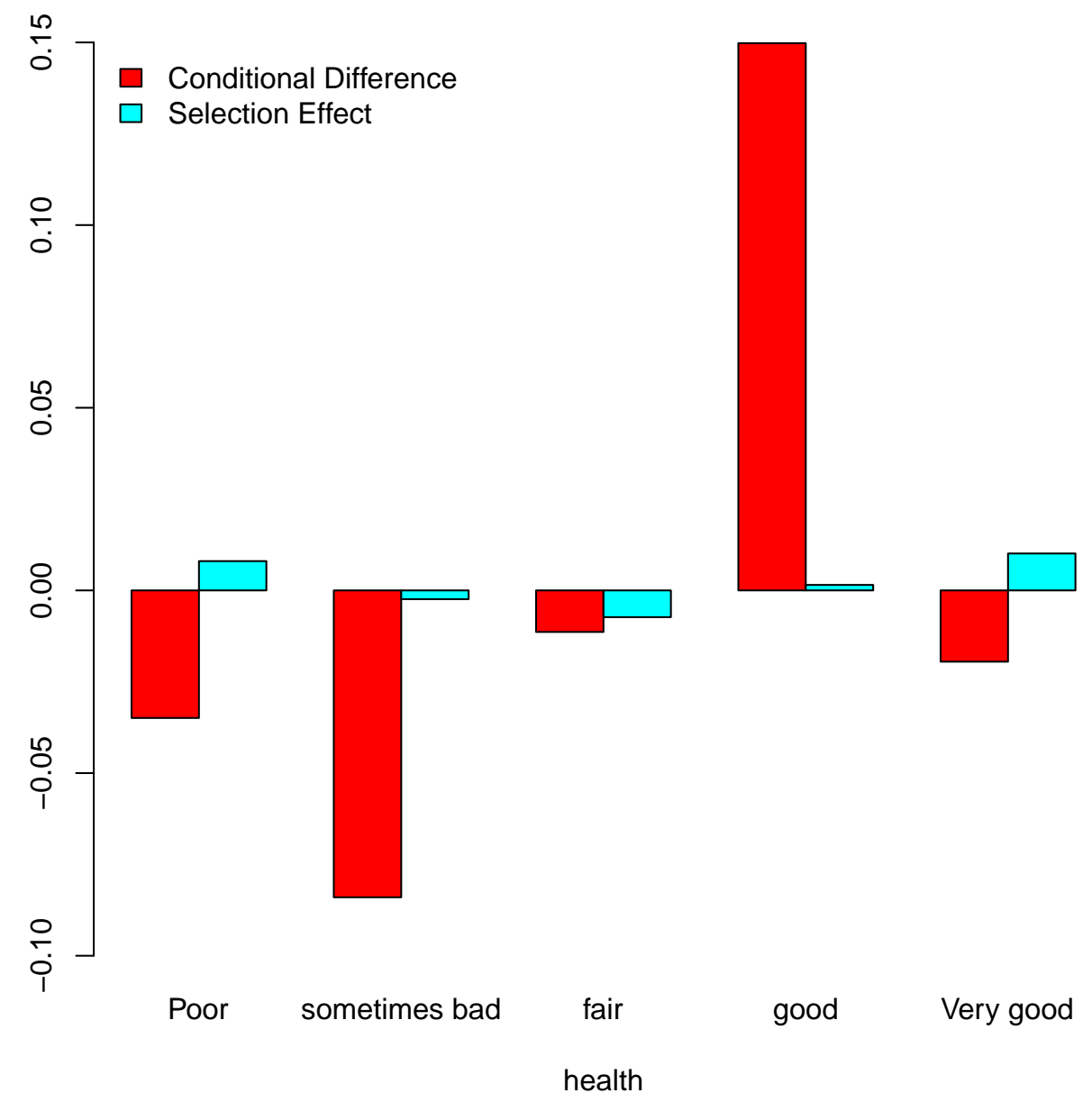

Figure 10: Decomposition of observed difference in the self-reported health into conditional differences and a selection effect, with binary education variable and two measurements for cognitive ability 